\title{
Discussion of a Study on the "Determination of Mainstream and Sidestream Cigarette Smoke Components for Cigarettes of Different Tobacco Types and a Set of Reference Cigarettes"
}

by

W.D.E. Irwin

British American Tobacco

Southampton, SO15 8TL, UK
The following discussion looks at some of the results of the paper by PERFETTI et al. (1) from a different perspective. Those results are in Tables 3 and 7 of PERFETTI et al. Tables in this discussion are identified by letter rather than number to avoid confusion.

The main purpose of the discussion is to suggest that sidestream (SS) and mainstream (MS) yields of a smoke component should be "normalised" to SS and MS tars respectively before calculating SS/MS ratios. With the ubiquitous use of filter ventilation, simple SS/MS ratios are subject to substantial variation and may be of limited value in understanding the smoke system.

BROWNE et al. (2) found that as ventilation increases $(0-83 \%)$, the SS/MS ratio for smoke nicotine increased (3.49-13.11) and PERFETTI et al. found a similar trend. This is because of the known reduction in mainstream nicotine with ventilation and the known relatively minor effect of ventilation on sidestream yields. It follows that, with the introduction of ventilation in many products, SS/MS ratios for many smoke components will have a very wide range, making this ratio of relatively little value in understanding the underlying system. However, if the SS and MS yields of component X (in this case nicotine) are "normalised" to SS and MS tar yields respectively, then a more useful ratio can be calculated. That ratio is SS yield of X per unit SS tar divided by MS yield of $X$ per unit MS tar.

In the case of nicotine/tar ratio (NTR) it is conveniently expressed as a percentage, or milligrams of nicotine per $100 \mathrm{mg}$ of tar.
Tables A - C use tobacco nicotine (\%), weight of nicotine consumed (mg), weight of tobacco consumed $(\mathrm{mg}), \mathrm{MS}$ and SS tar and nicotine $(\mathrm{mg})$ from tables of PERFETTI $e t$ al. to calculate other variables and construct scatter plots.

In Table A, "nicotine transfer" is the MS or SS nicotine $(\mathrm{mg})$ divided by weight of nicotine consumed (mg) expressed as a percentage. "NTR" was defined previously. "TANT" ("Tar Adjusted Nicotine Transfer") is the NTR (\%) divided by tobacco nicotine (\%). Table $\mathrm{B}$ gives the SS/MS nicotine ratios from Table 3 of PERFETTI et al. and, additionally, the SS/MS NTR ratios calculated from Table $\mathrm{A}$.

\section{DISCUSSION}

\section{Mainstream}

NTR is known to be influenced primarily by tobacco nicotine level with some additional effects from cigarette design factors:

1. NTR increases in proportion to tobacco nicotine, provided that cigarette design factors such as presence or absence of a filter, filter ventilation and cigarette paper permeability are held constant. This applies over a wide range of tobacco types.

2. The addition of a cellulose acetate filter increases NTR unless the tobacco is very alkaline, for example Burley.

3. Filter ventilation increases NTR. 
Mainstream and sidestream nicotine transfer, NTR and TANT values.

\begin{tabular}{l|c|c|c|c|c|c}
\hline Tobacco type & $\begin{array}{c}\text { Mainstream } \\
\text { Nicotine } \\
\text { Transfer (\%) }\end{array}$ & $\begin{array}{c}\text { Mainstream } \\
\text { NTR } \\
(\%)\end{array}$ & $\begin{array}{c}\text { Mainstream } \\
\text { TANT }\end{array}$ & $\begin{array}{c}\text { Sidestream } \\
\text { Nicotine } \\
\text { Transfer }\end{array}$ & $\begin{array}{c}\text { Sidestream } \\
\text { NTR }\end{array}$ & $\begin{array}{c}\text { Sidestream } \\
\text { TANT }\end{array}$ \\
\hline Flue-cured & 17 & 13.2 & 4.4 & 41 & 32.3 & 10.7 \\
Burley & 17 & 14.6 & 4.2 & 35 & 32.7 & 9.4 \\
Oriental & 14 & 3.5 & 4.4 & 39 & 7.5 & 9.4 \\
1R1 & 15 & 7.8 & 4.1 & 41 & 23.7 & 12.5 \\
2R1F & 13 & 7.5 & 4.3 & 42 & 24.7 & 14.3 \\
1R3F & 9 & 7.1 & 4.2 & 44 & 21.8 & 13.1 \\
1R4F & 6 & 9.7 & 5.0 & 45 & 27.8 & 14.4 \\
1R5F & 2 & 10.0 & 5.9 & 44 & 24.8 & 14.5 \\
\hline
\end{tabular}

Table B.

SS/MS ratios for nicotine and NTR.

\begin{tabular}{l|c|c}
\hline Tobacco Type & $\begin{array}{c}\text { SS/MS } \\
\text { Nicotine }\end{array}$ & $\begin{array}{c}\text { SS/MS } \\
\text { NTR }\end{array}$ \\
\hline Flue-cured & 2.4 & 2.4 \\
Burley & 2.1 & 2.2 \\
Oriental & 2.8 & 2.2 \\
1R1 & 2.8 & 3.0 \\
2R1F & 3.3 & 3.3 \\
1R3F & 4.8 & 3.1 \\
1R4F & 7.0 & 2.9 \\
1R5F & 23.6 & 2.5 \\
\hline
\end{tabular}

4. An increase in paper permeability gives some increase in NTR. Paper permeability data are not given by PERFETTI $e t$ al.

The eight cigarettes investigated by PERFETTI et al. exhibit a wide range of tobacco nicotines $(0.80-3.47 \%)$ and it might therefore be expected that this range would have a greater influence on NTR than other differences between these cigarettes. This is illustrated in Figure 1, "MS NTR versus tobacco nicotine".

Data labels in this and other Figures have the following meaning:

$\begin{array}{lllll}\mathrm{F} & = & \text { Flue-cured } & \text { No filter } & \\ \mathrm{B}= & \text { Burley } & \text { No filter } & \\ \mathrm{O}= & \text { Oriental } & \text { No filter } & \\ \mathrm{R} 1= & 1 \mathrm{R} 1 & \text { No filter } & \\ \mathrm{R} 1 \mathrm{~F}= & 2 \mathrm{R} 1 \mathrm{~F} & \text { Filter } & \text { No ventilation } \\ \mathrm{R} 3 \mathrm{~F}= & 1 \mathrm{R} 3 \mathrm{~F} & \text { Filter } & \text { No ventilation } \\ \mathrm{R} 4 \mathrm{~F}= & 1 \mathrm{R} 4 \mathrm{~F} & \text { Filter } & 29 \% \text { ventilation } \\ \mathrm{R} 5 \mathrm{~F}= & 1 \mathrm{R} 5 \mathrm{~F} & \text { Filter } & 73 \% \text { ventilation }\end{array}$

Figure 1 illustrates proportionality between NTR and tobacco nicotine, with some effect of ventilation. The $1 \mathrm{R} 4 \mathrm{~F}$ point ( $29 \%$ ventilation) is displaced "above the line" and this is more pronounced with $1 \mathrm{R} 5 \mathrm{~F}$ ( $73 \%$ ventilation). The data do not illustrate a shift "above the line" with the introduction of the cellulose acetate filter, but the expected relatively small effect may have been lost in the presence of larger effects from ventilation and, particularly, tobacco nicotine differences.

This proportionality with tobacco nicotine and the effect of ventilation are also apparent from the MS TANT values in Table A. Proportionality implies relatively constant TANT values, with a range of 4.1-4.4 before the introduction of $29 \%$ ventilation (5.0) and $73 \%$ ventilation (5.9).

Finally, on MS, Table A gives conventional nicotine transfers (smoke nicotine divided by weight consumed). The transfers indicate the expected substantial reductions that occur with filter ventilation, but, for many purposes, "tar adjusted nicotine transfer" is a more useful concept.

\section{Sidestream}

For mainstream, NTR and TANT are useful in "discounting" to a large extent the effects of physical design variables and tobacco nicotine on smoke nicotine. Discounting physical design variables is not so necessary for sidestream because they have less effect on relationships of interest.

Other things being equal, one might expect SS nicotine yield to be proportional to nicotine weight consumed, hence a fairly constant nicotine transfer for the eight cigarettes investigated by PERFETTI et al. Conventional SS nicotine transfers are given in Table A and they range from $35 \%$ to $45 \%$, though omitting the Burley cigarette gives a somewhat narrower range of 39 to $45 \%$. The relationship is also illustrated in Figure 2, "SS nicotine versus nicotine weight consumed".

Thus a primary factor in determining SS nicotine yield is, as expected, the weight of nicotine consumed. In their paper PERFETTI et al. state "These 


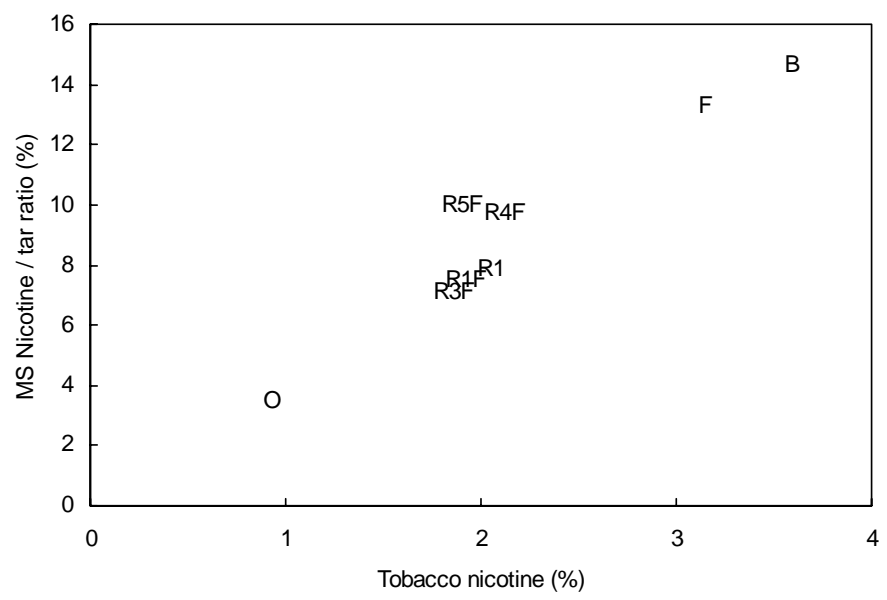

Figure 1.

Mainstream smoke NTR versus tobacco nicotine.

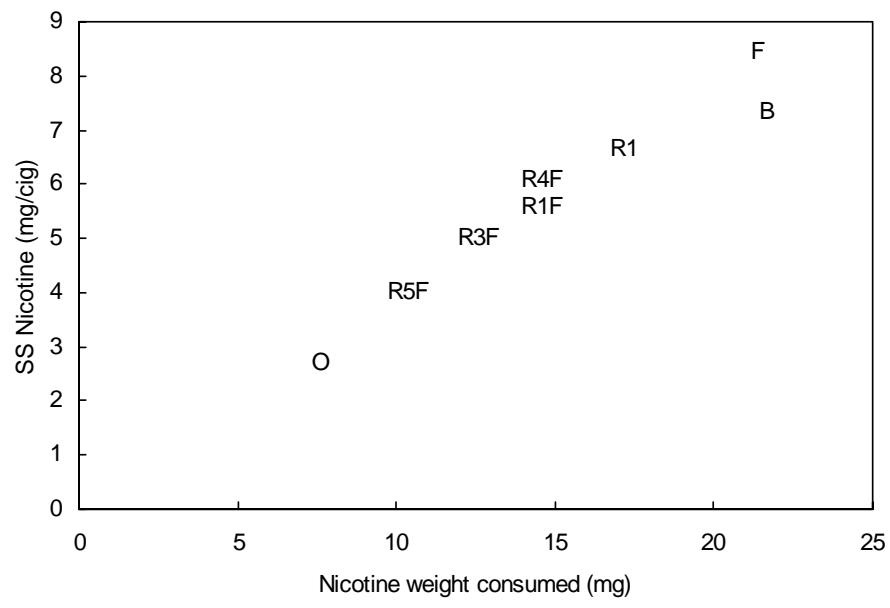

Figure 2.

Sidestream smoke nicotine versus nicotine weight consumed.

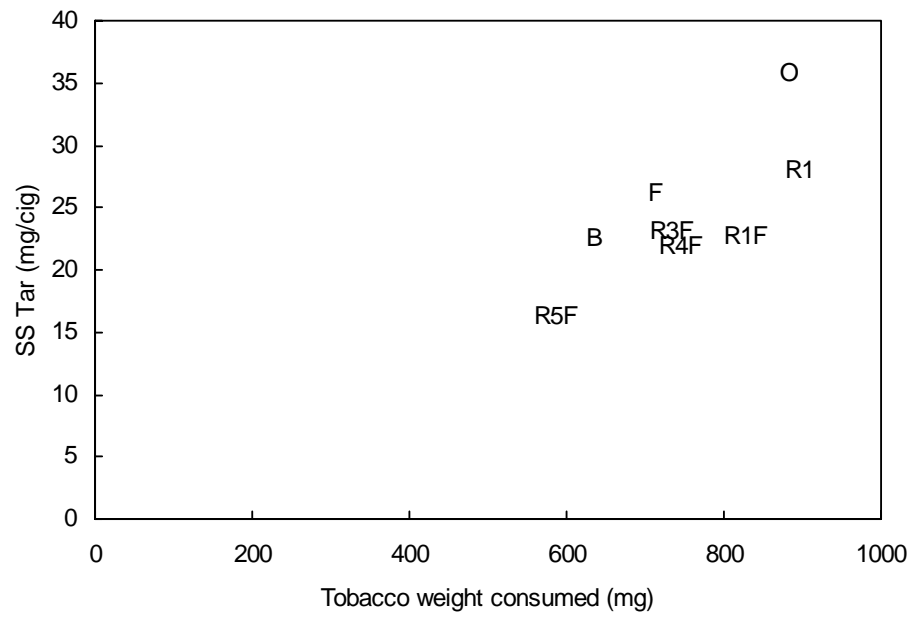

Figure 3.

Sidestream smoke tar versus tobacco weight consumed. 


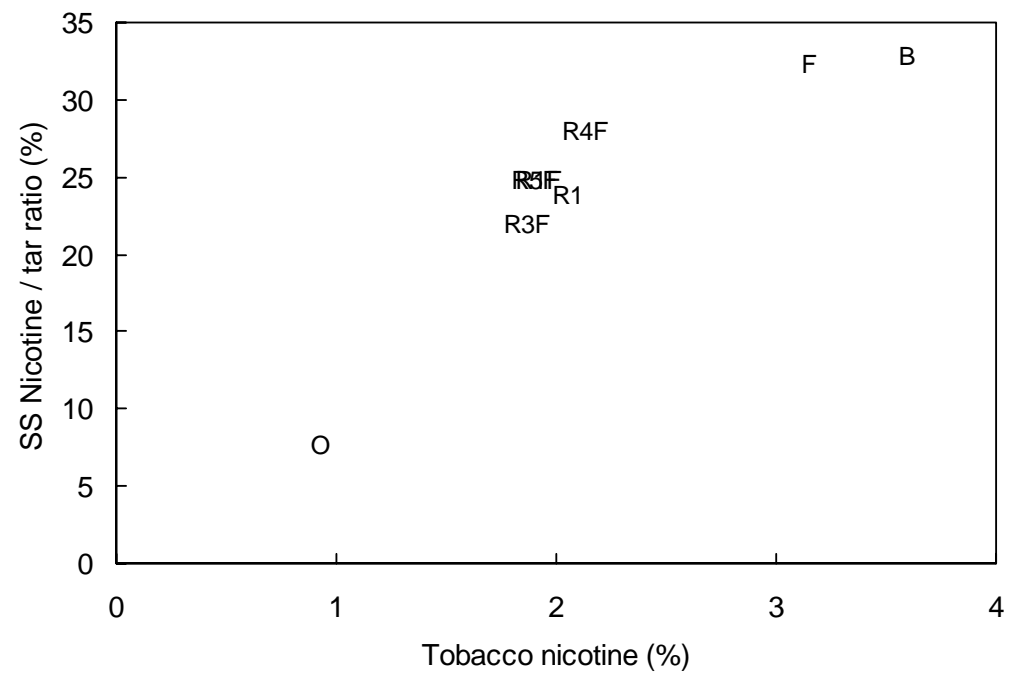

Figure 4.

Sidestream smoke NTR versus tobacco nicotine.

products' diversity also prevents the influence of any single construction parameter on SS yields being clearly found although a number of observations can be made." However, nicotine weight consumed, itself a function of tobacco weight consumed and tobacco nicotine (\%), is "clearly found" to be an influence on SS nicotine based on Figure 2.

Similarly, Figure 3, "SS tar versus tobacco weight consumed" does show the expected influence of tobacco weight on SS tar yield, though the relationship is not so obvious as between SS nicotine and nicotine weight consumed. From this Figure there is maybe a slight indication of a different slope for the five Kentucky cigarettes, compared with the 3 cigarettes of different tobacco type. Table $\mathrm{C}$ gives the $\mathrm{SS}$ tar results as a percentage of tobacco weight consumed.

Thus the range for the Kentucky cigarettes is 2.9-3.4\%, illustrating SS tar as a fairly constant proportion of tobacco weight consumed within this set. Values for the three "tobacco type" cigarettes are also in a fairly narrow range, $3.7-4.2 \%$. This is not a "filter / no filter" difference because 1R1 is non-filter, like the "tobacco type" cigarettes.

Previously in this discussion, SS/MS NTR was proposed as a more useful variable than conventional SS/MS nicotine. Calculated SS NTR and SS TANT values are given in Table A. If SS NTR were proportional to tobacco nicotine (\%) for this set of eight samples, then SS TANT values would be constant. In practice the range is fairly wide, 9.4-14.5. However, the results divide into two groups, 9.4-10.7 for the three "tobacco type" cigarettes and 12.5-14.5 for Kentucky Reference.

The relationship is illustrated in Figure 4, "SS NTR versus tobacco nicotine".

The SS/MS NTR ratios were given in Table B. The range was 2.2-3.3, much less of course than the range of the simple SS/MS nicotine ratios which are highly
Table C.

Sidestream smoke tar results as a percentage of tobacco weight consumed.

\begin{tabular}{l|c}
\hline & $\begin{array}{c}\text { SS Tar / } \\
\text { Tobacco Weight } \\
\text { Consumed (\%) }\end{array}$ \\
\hline Flue-cured & 3.8 \\
Burley & 3.7 \\
Oriental & 4.2 \\
1R1 & 3.3 \\
2R1F & 2.9 \\
1R3F & 3.4 \\
1R4F & 3.1 \\
1R5F & 3.0 \\
\hline
\end{tabular}

dependent on mainstream differences due to design differences.

In conclusion, SS/MS NTR ratio is relatively constant despite the wide range of blend and physical differences in this sample set. Whether it is similarly constant for other smoke components "normalised" to tar could be the subject for further research.

\section{REFERENCES}

1. Perfetti, T.A., W.M. Coleman III and W.S. Smith: Determination of mainstream and sidestream cigarette smoke components for cigarettes of different tobacco types and a set of reference cigarettes; Beitr. Tabakforsch. Int. 18 (1998) 95-113.

2. Browne, C.L., C.H. Keith and R.E. Allen: The effect of filter ventilation on the yield and composition of mainstream and sidestream smokes; Beitr. Tabakforsch. Int. 10 (1980) 81-90. 